\title{
Serum Trace Elements and Antioxidant Vitamins among Male Patients with Prostate Disorders in the Delta Region of Nigeria
}

\author{
Bhaguetai Joseph Aghawegbehe, ${ }^{1}$ Adedeji David Atere,,${ }^{1,2^{*}}$ David Bolaji Akinbo, ${ }^{3}$ Olumide \\ Faith Ajani, ${ }^{4}$ Raphael Usiosefe Erhunmwunse ${ }^{1}$ \\ ${ }^{1}$ Department of Medical Laboratory Science, University of Benin, Benin City, Edo State, Nigeria \\ ${ }^{2}$ Department of Medical Laboratory Science, Achievers University, Owo, Ondo State, Nigeria \\ ${ }^{3}$ Department of Medical Laboratory Science, Afe Babalola University, Ado Ekiti, Ekiti State, \\ Nigeria, ${ }^{4}$ Axios Foundation, Abuja, Federal Capital Territory, Nigeria
}

\section{Abstract}

Background: Prostate cancer remains the commonest form of cancer among Nigerian males, constituting $13.3 \%$ of all male cancers encountered in this region. Trace elements and antioxidant vitamins may be of epidemiological significance in the early prediction and treatment of prostate complications. The study aimed to explore the serum trace elements, antioxidant vitamins concentration and serum prostate specific antigen (PSA) among male with prostate disorders in the delta region of Nigeria.

Methods: Blood specimens were collected from males with symptoms of prostatitis $(n=70)$, benign prostatic hyperplasia $(\mathrm{BPH} ; \mathrm{n}=60)$ and prostate cancer $(\mathrm{PCa} ; \mathrm{n}=70)$, alongside with apparently healthy male subjects $(n=60)$. The levels of trace elements and antioxidant vitamins were evaluated. Fluorescence immunoassay technique was used to assess the expression of PSA.

Results: Compared with the controls, PCa patients had a significantly increased level of vitamin A $(\mathrm{p}<0.05)$, however, no significant differences in the serum levels of trace elements and antioxidant vitamins between subjects with prostate disorders and control group ( $p>0.05)$. Interestingly, there was a significant positive correlation between prostate specific antigen, trace elements and vitamins in BPH group $(\mathrm{p}<0.05)$.

Conclusions: Prostate disorders such as prostatitis, BPH and PCa may be associated with elevated levels of PSA, but, does not affect the circulating expression of some serum trace elements and antioxidant vitamins.

Keywords: Antioxidants, prostate disorder, prostate specific antigen, trace elements

\section{Introduction}

Prostate related complications account for approximately $25 \%$ of the reason males from late 40s visit the Urology clinics in Nigerian hospitals, including symptoms of prostatitis, benign prostatic hyperplasia (BPH) or Prostate Cancer (PCa). ${ }^{1}$ Although the main cause of BPH and $\mathrm{PCa}$ is not yet known, however, variations in the concentrations of some serum trace element such as zinc, copper, iron, cadmium, selenium and certain antioxidant vitamins such as Vit A, Vit $C$ and Vit $E$ are known to associate with the function of specific organs such as prostate, breast, muscle, stomach, kidney, and colon. Assessing the variations in trace elements and antioxidant vitamins, can be epidemiologically significant in the early prediction, identification, and treatment of prostate complications. ${ }^{2}$ Therefore, evaluating these trace elements and antioxidant vitamins could be useful in preventing some adverse clinical conditions and complications that can result in death due to the insufficiency or excess availability of these biochemical analytes in prostate complications. ${ }^{3}$

The prostate contains some smooth muscles that help in expelling seminal fluid during ejaculation. This relatively alkaline, milky fluid secreted by the prostate nourishes and

Correspondence: A. D. Atere, Department of Medical Laboratory Science, Achievers University, Owo, Nigeria. E-mail: ateread@gmail.com, Tel.: +2348039501172 
protects the sperm. In humans, the seminal fluid is largely composed of simple sugars and accounts for about 30\% of semen volume with spermatozoa and fluid from the seminal vesicle. The protein composition is less than $1 \%$ and comprises of prostate specific antigen (PSA), prostatic acid phosphatase, proteolytic enzymes and beta-microseminoprein. Prostate secretions also contain zinc, having a concentration of 500 to 1000 times more than the zinc concentration in the blood. The prostatic normal functions are regulated by dihydrotestosterone, which is mainly produced by the testicle. ${ }^{4}$

An apparently healthy prostate is approximately the size of a walnut, and grows consistently bigger as the age increases. However, problems can arise when it grows too large as commonly seen from age 40 . Thus, the risk of prostate complications increases dramatically with age as men increase in age too. Prostate cancer is a tumor of the prostate gland, representing one of the most common cancers affecting older men in developed countries and a major cause of death for aged men. ${ }^{5}$ Some previous reports have revealed high prevalence of prostate cancer in Nigeria; with prevalence rates of $127 / 100,000$ men in 1997 and 114/100,000 men in 2002. ${ }^{6,7}$ Prostate cancer is the commonest cancer among Nigerian males and has been estimated to constitute $13.3 \%$ of all male cancers. ${ }^{8}$ It has been documented that the serum levels of PSA is widely used as a biomarker for early detection of prostate complications and its elevation in the serum is suggestive of prostate disorders. ${ }^{9}$

Trace elements are vital components of body fluids and tissues which are required by the body in small amounts (usually less than 1 to 10 parts per million) for a range of functions. Metals such as iron and copper are required by the human body in trace (milligram) quantities, while other metals like the chromium, manganese, fluoride, iodide, cobalt, selenium, silicon, arsenic, boron, and vanadium are only needed in ultra-trace (microgram) quantities. ${ }^{10}$ Trace elements are major components of living structures and various studies have proven their existence in various forms keeping a dynamic balance status in the human body. ${ }^{11}$ Variations in the concentration of trace elements and antioxidant vitamins affect the proper functioning of different organs and tissues in the body. The insufficiency or excess of trace elements can prompt body metabolic disorder and cellular growth disturbance, even mutation and cancerization. ${ }^{11,12}$ This study therefore investigated the relationship between serum trace elements and antioxidant vitamins status of subjects with prostate disorders in the Nigeria delta region and their possible utilization in the management of prostate complications.

\section{Methods}

This research was conducted in Warri, Delta State, Nigeria. A total of 200 male subjects aged 48 to 80 years who attended the Urology clinics in four hospitals in Warri (Warri General Hospital, Westend Hospital, Lilly Hospital and Capitol Hill Hospital) were recruited as subjects for this study, and were further grouped into three, comprising of patients with prostatitis $(n=70)$, BPH $(n=60)$ and PCa $(n=70)$.

The durations of the prostate disorders at the point of sample collection were 0 to 1 year for prostatitis, 0 to 5 years for $\mathrm{BPH}$ and 0 to 5 years for PCa. Only subjects presenting with symptoms of prostatitis, BPH and PCa with known PSA values were recruited for this research. Male subjects who did not have prostate related complications and those who were presenting with other renal disorders were excluded from the study. A pre-designed structural questionnaire was utilized to collect bio-data, clinical data and socio-demographic characteristics of the patients. As control group, 60 apparently healthy adult male subjects who were age and socio-economic status matched were included.

Subjects participating in this study were fully briefed on the research protocols in the clinics after which they were required to sign a written consent. Ethical approval for the study was obtained from Delta State Hospital Management Board ethical review committee with registration number CHW/ ECC.VOL1/072.

Five milliliters $(5 \mathrm{ml})$ of venous blood was aseptically collected using standard phlebotomy technique. Serum obtain adequate amount of serum for the analysis. Serum was separated from the blood after retraction by centrifuging for 5 minutes at $4000 \mathrm{rpm}$, into micro centrifuge tubes and stored at -200C until time of analysis.

The trace elements were analysed using Single quadrupole ICP-MS (Thermo Scientific Co., MA, USA). Vit A and Vit E were analysed using an integrated analytical system of HPLC 2695 (Waters GenTech Scientific Inc., NY, USA) Integrity System equipped with a UVVIS detector (Waters 996) with the range of 
Table 1 Serum Levels of Trace Elements (Iron, Copper, Selenium) and Vitamins (Vit A and Vit E) and Prostate Specific Antigen of Study Subjects of Patients with Prostate Disorders Attending the Urology Clinics in Nigerian Hospitals

\begin{tabular}{lccc}
\hline \multicolumn{1}{c}{ Parameters } & Patients $(\mathbf{n = 2 0 0 )}$ & Control (n=60) & P-value \\
\hline Fe $(\mu \mathrm{g} / \mathrm{dl})$ & $113.93 \pm 3.17$ & $116.25 \pm 5.04$ & 0.701 \\
$\mathrm{Cu}(\mu \mathrm{g} / \mathrm{dl})$ & $130.78 \pm 2.04$ & $136.65 \pm 5.47$ & 0.332 \\
$\mathrm{Se}(\mu \mathrm{g} / \mathrm{l})$ & $0.46 \pm 0.01$ & $0.47 \pm 0.02$ & 0.734 \\
Vit A $(\mu \mathrm{g} / \mathrm{l})$ & $65.37 \pm 1.11$ & $64.00 \pm 3.12$ & 0.687 \\
Vit E $(\mu \mathrm{g} / \mathrm{l})$ & $1.04 \pm 0.03$ & $1.09 \pm 0.05$ & 0.501 \\
PSA $(\mathrm{ng} / \mathrm{dl})$ & $19.29 \pm 2.45$ & $1.15 \pm 0.85$ & $0.000^{*}$ \\
\hline
\end{tabular}

Note: $\mathrm{Fe}=$ Serum Iron, $\mathrm{Cu}=$ Serum Copper, Se=Serum Selenium, Vit A=Vitamin A, Vit E=Vitamin E, PSA=Prostate specific antigen; Values are expressed as mean \pm SD, * Significant at $\mathrm{p} \leq 0.05$

190-800 nm. Chromatographic separations were performed on a LC-NH2-NP column (25 $\mathrm{cm} 4.6 \mathrm{~mm}, 5 \mu \mathrm{m}$ ) with the Supelguard TM LC-NH2-NP precolumn SUPEL-CO (Merck, Taufkirchen, Germany). The PSA was analysed using ICHROMATM PSA (Boditech Med, UK) which was a fluorescence immunoassay (FIA) for the quantitative determination of PSA.

Data obtained were analysed using descriptive and inferential statistical tools. Descriptive statistics were mean \pm standard deviation (S.D), while inferential statistics used were student t-test, Analysis of Variance with post hoc to access the source of significance and Pearson correlation using the Statistical Package for Social Sciences (SPSS version 21.0, Chicago, IL) software. The level of significance was set at $\mathrm{p}<0.05$.

\section{Results}

This study explored the levels of serum trace elements (iron, copper, selenium) and antioxidant vitamins (Vit A, and Vit E) among patients with prostatitis, BPH, PCa and compared with healthy male subjects as a control group. Result showed that no significant difference in the levels of serum trace elements (iron, copper, selenium) and antioxidant vitamins (Vit A and Vit E) between prostate disorders patients in general and control group $(p>0.05)$ (Table 1), however, the level of serum PSA was significantly increased in the prostrate disorder group compared to the control $(\mathrm{p}<0.000)$.

Interestingly, serum iron levels in the $\mathrm{BPH}$ group were significantly decreased $(\mathrm{p}<0.05)$

Table 2 Serum Levels of Trace Element (Iron, Copper, Selenium) and Vitamins (Vit A and Vit E) and Prostate Specific Antigen of Patients with Prostate Disorders, Including Prostatitis, Benign Prostatic Hyperplasia or Prostate Cancer Attending the Urology Clinics in Nigerian Hospitals

\begin{tabular}{lcccc}
\hline \multicolumn{1}{c}{ Parameters } & $\begin{array}{c}\text { Control } \\
(\mathbf{n = 6 0})\end{array}$ & $\begin{array}{c}\text { Prostatitis } \\
(\mathbf{n = 7 0 )}\end{array}$ & $\begin{array}{c}\text { BPH } \\
(\mathbf{n = 6 0})\end{array}$ & $\begin{array}{c}\text { Prostate Cancer } \\
(\mathbf{n = 7 0})\end{array}$ \\
\hline $\mathrm{Fe}(\mu \mathrm{g} / \mathrm{dl})$ & $116.25 \pm 16.89$ & $119.69 \pm 21.22 \mathrm{a}$ & $105.88 \pm 25.71 \mathrm{~b}$ & $120.19 \pm 14.79 \mathrm{a}$ \\
$\mathrm{Cu}(\mu \mathrm{g} / \mathrm{dl})$ & $136.66 \pm 18.31$ & $133.42 \pm 19.92 \mathrm{a}$ & $128.03 \pm 15.40 \mathrm{a}, \mathrm{b}$ & $130.98 \pm 9.50 \mathrm{a}, \mathrm{b}$ \\
$\mathrm{Se}(\mu \mathrm{g} / \mathrm{l})$ & $0.47 \pm 0.07$ & $0.49 \pm 0.09$ & $0.43 \pm 0.10 \mathrm{a}$ & $0.49 \pm 0.06$ \\
$\mathrm{Vit} \mathrm{A}(\mu \mathrm{g} / \mathrm{l})$ & $64.16 \pm 9.75$ & $63.88 \pm 12.96$ & $58.77 \pm 9.44 \mathrm{a}$ & $72.70 \pm 3.90 \mathrm{~b}$ \\
$\mathrm{Vit} \mathrm{E}(\mu \mathrm{g} / \mathrm{l})$ & $1.09 \pm 0.17$ & $1.09 \pm 0.22$ & $0.83 \pm 0.33 \mathrm{a}, \mathrm{b}$ & $1.15 \pm 0.13 \mathrm{a}$ \\
$\mathrm{PSA}(\mathrm{ng} / \mathrm{dl})$ & $1.15 \pm 0.85$ & $7.04 \pm 2.03 \mathrm{a}$ & $19.80 \pm 6.96 \mathrm{a}, \mathrm{b}$ & $68.38 \pm 30.25 \mathrm{a}, \mathrm{b}, \mathrm{c}$ \\
\hline
\end{tabular}

Note: $\mathrm{Fe}=$ Serum Iron, $\mathrm{Cu}=$ Serum Cupper, Se=Serum Selenium, Vit A= Vitamin A, Vit E= Vitamin E, PSA= Prostate specific antigen; Values are expressed as mean $\pm S D$, aSignificantly different from control group at $p<0.05$, bSignificantly different from prostatitis group at $\mathrm{p}<0.05$, cSignificantly different from BPH group at $\mathrm{p}<0.05$ 
Table 3 Correlation of Trace Elements and Vitamins among Patients with Prostate Disorders

\begin{tabular}{|c|c|c|}
\hline & $\mathbf{R}$ & $\mathbf{P}$ \\
\hline \multicolumn{3}{|c|}{ Prostatitis (n=70) } \\
\hline $\mathrm{Fe}(\mu \mathrm{g} / \mathrm{l})$ & 0.02 & 0.85 \\
\hline $\mathrm{Cu}(\mu \mathrm{g} / \mathrm{l})$ & -0.01 & 0.95 \\
\hline $\operatorname{Se}(\mu \mathrm{g} / \mathrm{l})$ & 0.02 & 0.85 \\
\hline Vit A ( $\mu \mathrm{g} / \mathrm{l})$ & -0.02 & 0.93 \\
\hline Vit E ( $\mu \mathrm{g} / \mathrm{l})$ & -0.02 & 0.93 \\
\hline \multicolumn{3}{|l|}{$\mathrm{BPH}(\mathrm{n}=60)$} \\
\hline $\mathrm{Fe}(\mu \mathrm{g} / \mathrm{dl})$ & 0.01 & 0.94 \\
\hline $\mathrm{Cu}(\mu \mathrm{g} / \mathrm{dl})$ & 0.10 & 0.45 \\
\hline $\operatorname{Se}(\mu \mathrm{g} / \mathrm{l})$ & 0.01 & 0.93 \\
\hline Vit A ( $\mu \mathrm{g} / \mathrm{l})$ & 0.71 & $0.00^{*}$ \\
\hline Vit E ( $\mu \mathrm{g} / \mathrm{l})$ & -0.82 & $0.00^{*}$ \\
\hline \multicolumn{3}{|c|}{ Prostate cancer $(n=70)$} \\
\hline $\mathrm{Fe}(\mu \mathrm{g} / \mathrm{dl})$ & -0.20 & 0.21 \\
\hline $\mathrm{Cu}(\mu \mathrm{g} / \mathrm{dl})$ & 0.12 & 0.44 \\
\hline $\operatorname{Se}(\mu \mathrm{g} / \mathrm{l})$ & -0.20 & 0.21 \\
\hline Vit A ( $\mu \mathrm{g} / \mathrm{l})$ & -0.34 & 0.08 \\
\hline Vit E ( $\mu \mathrm{g} / \mathrm{l})$ & 0.09 & 0.65 \\
\hline
\end{tabular}

Note: * Correlation is significant at the 0.05 level (2-tailed)

compared to the control group and other prostatic disorders, while it significantly increased $(\mathrm{p}<0.05)$ in the prostate cancer group than other test groups and control group. Serum Vit A levels was also significantly increased $(\mathrm{p}<0.05)$ in the group with prostatic cancer compared with other test groups and control group. There were significant increases $(p<0.05)$ in the PSA levels of the various test groups with prostatitis, BPH and prostatic cancer respectively compared with the control group (Table 2). Other serum trace elements and antioxidant vitamins however showed no significant difference between the various study groups $(p>0.05)$. The relationship between the variables in the control, prostatitis, BPH and prostate cancer with PSA were assessed (Table 3). Iron, Copper, Selenium, Vit A and Vit E showed significant positive relationship of the control subjects with PSA, while other groups showed no significant correlation with PSA. Vit A and Vit E however showed very high significant positive and negative relationship respectively with PSA ( $\mathrm{r}=0.71$ and $\mathrm{r}=-0.82)$.

\section{Discussion}

Serum expressions of trace elements such as $\mathrm{Fe}, \mathrm{Cu}$, and $\mathrm{Se}$, some antioxidant vitamins (Vit $A$ and Vit E) and PSA, have been assessed in male patients with prostate disorders and apparently healthy controls. The prostate disorders patients include male presenting with symptoms of prostatitis, $\mathrm{BPH}$ and prostate cancer who have known PSA values. The presence of trace elements and antioxidant vitamins has been associated with the proper functioning of different organs and tissues. ${ }^{11}$ However, our result shows that there is no difference in the serum levels of most of the trace elements (copper, selenium) and antioxidant vitamin namely Vit $\mathrm{E}$ between subjects with prostate disorder and the control group, however, only iron and Vit A has shown an increased levels in the prostate cancer group, suggesting that cancer of the 
prostate alters the serum concentration of these analytes. Contrarily, Onyema-iloh et al. ${ }^{3}$ has reported significantly reduced serum levels of selenium, zinc, vitamin $\mathrm{E}$ and $\mathrm{C}$, and higher levels of copper, when compared to the apparently healthy control group.

Some trace elements have been reported of playing a major role in the biology of cancer; however, there is still a gap in our understanding of the relationship between the function of trace elements and the initiation, advancement and inhibition of carcinogenic process of the prostate gland. ${ }^{13}$ Trace elements are a major constituent of biological structures, albeit the increasing queries on the toxicity of these elements to human health at concentrations higher than required for biological functions and whether they are truly essential. In this study, there was no significant difference in the serum expression of trace elements and vitamins in the prostatitis and BPH test subjects when compared to the control group. This finding contradicts other studies on the association of trace elements and some vitamins with prostate disorders. ${ }^{2,3,14-16}$ On the other hand, a significant increase in the serum level of Vit A was observed in the prostatic cancer group compared to the control with other vitamins and trace elements showing no significant difference which negates the reports of other previous similar studies. ${ }^{3}$

Furthermore, PSA is observed to be positively correlated with trace elements and vitamins in the control subjects. Vitamin A, its natural and synthetic analogs have been reported to enhance prostate cancer risks and it is remarkable that the BPH group investigated in this study showed positive correlation of PSA with vitamin A. One mechanism of Vit A enhancement of cancer risk is by its interaction with zinc which could result in the proliferation of prostatic epithelial cells. ${ }^{17}$ There is however a concurrent negative correlation of PSA with vitamin $\mathrm{E}$ in the $\mathrm{BPH}$ group investigated in the study. Various forms of Vit E possess antiinflammatory and antioxidant properties and have been reported to have numerous benefits for men with prostate disorders including inhibiting the growth of human and animals' prostate tumors. ${ }^{18}$ There was no significant correlation between PSA, trace elements and vitamins in the other test groups. This study therefore suggests that a variation in the serum levels of PSA does not affect the concentration of trace elements and vitamins present in these subjects. This is consistent with the findings of Donkena et al. ${ }^{19}$ showing that daily intake of Vit A, Vit E or serum $\alpha$-tocophenrol does not correlate with increased prostate cancer risk. Several studies have shown a correlation between prostate disorders and elevated serum levels of PSA. ${ }^{2,20}$ The patients with prostatitis, BPH and Pca showed higher levels of PSA than the control group thereby correlating with the studies listed above.

The limitation of study is lacking data on the correlation between multivitamin usage and a family history of cancer. Although the association of vitamins usage and elevation of PSA has been established in prostate disorders, information about the duration of vitamin and trace element use could have been relevant in determining if their correlation is restricted to long-term users.

As a conclusion, prostate disorders such as prostatitis, benign prostatic hyperplasia and prostate carcinoma are associated with elevated levels of prostate specific antigens (PSA), with no significant alteration in the serum levels of some trace elements and antioxidant vitamins. These findings reveal the lack of clinical significance of these trace metals and vitamins as screening tools for the diagnosis and therapy of prostate complications and disorders. Further studies are encouraged to uncover the mechanistic role of trace elements and vitamin supplements in the elevation of PSA in prostate disorders and critical areas of early detection that several investigators have not been able to explore.

Acknowledgments: Authors appreciate the support of all the participants and they are grateful to the staff of the various hospitals for their cooperation in specimens collection. We are also grateful to Prof. H.B. Osadolor for his help in the study design.

Conflicts of Interest: The authors declare that this manuscript was approved by all authors and no competing interest exists.

Funding: Self-sponsored

\section{References}

1. Bracarda S, de Cobelli O, Greco C, PrayerGalleti T, Valdagni R, Gatta G, et al. Cancer of the prostate. Crit Rev Oncol Hematol. 2005;56(3):379-96.

2. Kaba M, Pirincci N, Yuksel MB, Gecit I, Gunes M, Ozveren H, et al. Serum levels of trace elements in patients with prostate cancer. Asian Pac J Cancer Prev. 2014;15(6):26259.

3. Onyema-iloh BO, Meludu, SC, Iloh E, Nnodim I, Onyegbule O, Mykembata B. Biochemical changes in some trace 
elements, antioxidant vitamins and their therapeutic importance in prostate cancer patients. Asian Journal of Medical Science. 2015;6(1):95-7.

4. Adedapo KS, Arinola OG, Shittu OB, Kareem OI, Okolo CA, Nwobi LN. Diagnostic value of lipids, total antioxidants, and trace metals in benign prostate hyperplasia and prostate cancer. Niger J Clin Pract. 2012;15(3):293-7.

5. Cedars MI, Taymans SE, DePaolo LV, Warner L, Moss SB, Eisenberg ML. The sixth vital sign: what reproduction tells us about overall health. Proceedings from a NICHD/CDC workshop. Hum Reprod Open. 2017;2017(2):hox008

6. Kolawole A0. Feasible cancer control strategies for Nigeria: mini-review. American Journal of Tropical Medicine \& Public Health. 2011;1(1):1-10.

7. Duru R, Njoku O and Maduka I. Oxidative stress ilndicators in patients with prostate disorders in Enugu, South-East Nigeria. Biomed Res Int. 2014;2014:313015.

8. Ezenwa EV, Tijani KH, Jeje A, Ogunjimi A, Ojewola, R. Prevalence of Prostate Cancer among Nigerians with Intermediate Total Prostate Specific Antigen Levels (4-10ng/ $\mathrm{Ml}$ : Experience at Lagos University Teaching Hospital, Nigeria. The Internet Journal of Urology. 2012;9(3):1-5.

9. Pérez-Ibave DC, Burciaga-Flores $\mathrm{CH}$, Elizondo-Riojas MÁ. Prostate-specific antigen (PSA) as a possible biomarker in non-prostatic cancer: A review. Cancer Epidemiol. 2018;54:48-55.

10. Zaichick V, Zaichick S. Ratios of selenium/ trace element contents in prostate gland as carcinoma's markers. J Tumor Med Prev. 2017;1(2):1-12.

11. Navarro SA, Rohan TE. Trace elements and cancer risk: a review of the epidemiologic evidence. Cancer Causes Control. 2007;18(1):7-27.

12. Demir C, Demir H, Esen R, Sehitogullari A, Atmaca M, Alay M. Altered serum levels of elements in acute leukemia cases in Turkey. Asian Pac J Cancer Prev. 2011;12912):3471-4.

13. Geraki K, Farquharson MJ, Bradley DA. Concentrations of $\mathrm{Fe}, \mathrm{Cu}$ and $\mathrm{Zn}$ in breast tissue: a synchrotron XRF study. Phys Med Biol. 2002;47(13):2327-39.

14. Mahabir S, Spitz MR, Barrera SL, Beaver SH, Etzel C, Forman MR. Dietary zinc, copper and selenium and risk of lung cancer. Intl J of Cancer. 2007; 120(5):1108-15.

15. Zowczak M, Iskra M, Torlinski L, Cofta S. Analysis of serum copper and zinc concentration in cancer patients. Biol Trace Elem Res. 2001;82(1-3): 1-8.

16. Adaramoye OA, Akinloye O, Olatunji IK. Trace elements and Vitamin $\mathrm{E}$ status in Nigerian patients with prostate cancer. Afr Health Sci. 2010;10(1):2-8

17. Mondul AM, Watters JL, Mannisto S, Weinstein SJ, Snyder K, Virtamo J, et al. Serum retinol and risk of prostate cancer. Am J Epidemiol. 2011;173(7):813-21.

18. Huang Y, Wu R, Su ZY, Guo Y, Zheng X, Yang $\mathrm{CS}$, et al. A naturally occurring mixture of tocotrienols inhibits the growth of human prostate tumor, associated with epigenetic modifications of cyclin-dependent kinase inhibitors p21 and p27. J Nutr Biochem. 2017;40:155-63.

19. Donkena KV, Karnes RJ, Young CYF. Vitamins and prostate cancer risk. Molecules. 2010;15(3):1762-83.

20. Vardhan SP, Krishnamma M, Naidu JN, Naidu MP. Study of insulin resistance and antioxidant vitamin status in prostate cancer patients. International Journal of Medical Science. 2014;2(2):643-6. 